\title{
Introduction: Technology and International Relations - The New Frontier in Global Power
}

\section{Giampiero Giacomello, Francesco Niccolò Moro and Marco Valigi}

\section{TECHNOLOGY, HUMAN NATURE AND INTERNATIONAL POLITICS}

Thucydides, who is considered the 'father' of modern international relations (IR) theory, was able to leave 'a possession for all time' because he centered his magnus opus, The Peloponnesian War, on the only 'immutable' element of human history - namely, human nature. Centuries later, this led another giant thinker, General Carl von Clausewitz, also to conclude in his magnus opus, Vom Kriege, that while all conflicts are different, the nature of war is immutable; it never changes, because war is a human endeavor. If human nature remains the same, how can the nature of war change? It is just the tools that are different. Technology is one of such tools. Or, rather, it is the formulas, ingenuity, and organization of resources that enable the production and improvement of such tools. Therefore, technology is a multiplier.

Technology plays a central role in human life. Economy, medicine, and warfare are all deeply shaped by technological change. If human nature is the constant, technology is the variable that makes historical evolution what it is. Unsurprisingly, technology transformation does influence the relationship among individuals and organizations, not only in domestic politics but also in the international system. Much as technology has evident, positive effects on the well-being of societies, humans have always displayed mixed, complex reactions to technology itself (Brosnan, 2002).

Such 'fears' are particularly acute regarding computers because they are perceived to have some 'thinking' capabilities. Despite the reassurances of computer scientists that the machines do what they are programmed to do, part of public opinion has always had some misgivings (Dinello, 2005). Artificial intelligence (AI) has now brought that suspicion to a new level of 
alarm, because this time, machines fueled by AI seem capable of autonomous thinking and decision making. If these conditions were to be extended to the military and generate lethal autonomous weapons, a sense of doom would become, if not justified, at least comprehensible. It is indicative than no less that Henry Kissinger, a scholar who spent many years investigating limited wars and nuclear weapons, reached out to the public by writing an angst-ridden article in The Atlantic to warn the world of such dangers (Kissinger, 2018). This ambivalent attitude by human beings is likely to increase, as the contributions to this book show, because technology is now pervasive and only certain to become more so.

But what about states? Even for them, technology is a source of empowerment and, at the same time, of concern. The impact that technology has on key aspects of political and social life is the subject of private and public discussions daily. Take how global media outlets present competition on telecommunication infrastructure as a key feature of today's international power politics. On the one hand, advances in information communication technologies (ICTs) are widely believed to have given a boost to US power in the past decades. The US military has long considered technology as the core of its primacy. National security strategies have repeatedly treated technology as a means to give the United States an edge over competitors and as a source of concern about possible implications of increasing accessibility of disruptive technologies for rival nations and non-state actors. American tech companies are still dominant on the business scene. Most recently, the so-called FAGA (Facebook, Amazon, Google, and Apple) companies seem to have supplanted major oil companies as the embodiment of global success in the US economy. Yet, on the other hand, in the last few years, some in the US have been seeing American technological edge eroding. The U.S.-China Economic and Security Review Commission - a Congress-mandated body - has recently restated that China's practices over technology transfers, use of 'illicit means' to achieve technological leadership, and investment in 'next-generation defense technologies' are some of the major reasons for concern for US global power. The business sector is affected too: the fate of the company Huawei - which aims to provide infrastructures for $5 \mathrm{G}$ technologies around the world - is one of the most immediate images of China-US growing rivalry, at least by looking at the newspapers' headlines.

The centrality of technology as a tool for harnessing wealth and power in the twenty-first century is recognized outside the US and China. European Union member states - and the European Commission - have been promoting awareness on the centrality of combining science and technology strategies in public policy discourses, planning and implementation, and research funds allocation. European initiatives in the civilian domain, such as those to promote so-called key enabling technologies (micro- and nanoelectronics, 
nanotechnology, industrial biotechnology, advanced materials, photonics, and advanced manufacturing technologies) have been central in EU's industrial policy for a decade.

Finally, non-state actors and illegal/criminal organizations perceive technology as an instrument with which to ensure their persistence and the achievement of their objectives. Technology can function as a vector of ideas, a means of task circulation/division of work within the organization, and a power multiplier (i.e., as a source of tactical advantage in implementing the strategies of those actors). In particular, for minorities pursuing goals that are mostly not compatible with those of political institutions, or part of an illicit plan, as in the case of criminal organizations, non-state actors look at technological change as a potential source of advantage and resilience vis-à-vis powerful players.

\section{AN (INEVITABLY) SHORT LITERATURE REVIEW}

If technology represents such a huge factor in the evolution of the economy, medicine and warfare, it is not surprising that the literature about it is equally large. Science and technology embody a theoretical and empirical intersection among different disciplines, such as sociology, history, and anthropology (Sismondo, 2004). However, IR, international political economy (IPE) and security studies have often failed to incorporate the importance of technological innovation and its spread (Horowitz, 2010). The nexus among the evolution of international environment and technological trends has been occasionally investigated (Hanson, 2008; Herrera, 2006; McNeill, 1982; Ogburn, 1949; Sanders, 1983; Skolinkoff, 1993; Van Creveld, 1989), without specifically connecting with the major research questions of IR theory.

While in 1950s and 1960s, the impressive growing of technology promoted uncertainties about human control over machines and the evolution of technology (Winner, 1977), in the 1980s and 1990s, the spread of large 'socio-technical systems' (Fritsch, 2011, p. 28) among industrialized societies generated questions - though not systematically - about their political implications (Smith and Marx, 1994; Winner, 1986). Far from political economists', such as Karl Marx and Adam Smith, idea of an effective and autonomous vector of historical change, in that period technology was also identified as a reason for oppression and as a generator of new challenges (Vig, 1988).

Transnational threats, international terrorism, and the global economic turmoil accompanied the international scenario of the 2000s (Fearon, 1994; Powell, 1999; Smith and Stam, 2004), stimulating speculations about the role of information technology as a possible optimizer of the US military strategy. While the US led - quoting Andrew Krepinevich (1994) - the 'cavalry to computer' transition, the robotics revolution will impact extensively on future 
warfare - thus, benefits for America and its allies seemed to be coupled with rising risks (Singer, 2009).

Most IR scholars have considered technology as an exogenous variable that can only impact on minor features of international affairs, perhaps with exceptions such as nuclear weapons or the Internet, and not as a central matter of inquiry and methodological debate. At the same time, major concerns about international security and military affairs cannot be explained without reference to the number of people and technologies involved (Brooks, 2007, p. 228). Assuming that technology is not a mere practical application of material sciences, technological change will be encompassed among the key explanatory variables of international politics. However, a multidisciplinary approach that also takes account of the impact of decisions (both at individual and organizational level) and norms of the evolution of technology is far from being developed.

This book aims to fill (at least) some of the existing theoretical and empirical gaps in the field of IR, security studies, and defense transformation that we have mentioned above and to investigate the implications of technological change in international affairs, emphasizing the relation between technological transformation and socio-political variables. In the last decades, to some extent, technological change has reshaped the global distribution of power and interests by empowering emerging countries and non-state actors, but that process has been neither progressive nor homogeneously distributed among world regions and countries. Notwithstanding that the occurrence of some breakthroughs makes the patterns of technological evolution difficult to foresee in exact or clear terms, we remain convinced (as we do in this book) that a thorough analysis of the macro-dynamics governing technological change is the only reasonable choice for international actors and public opinion to direct that change towards bettering the conditions of planet Earth and not contributing to its demise.

\section{STRUCTURE OF THE BOOK}

Given the huge number of economic, industrial, health, and social areas affected by advanced technologies, a comprehensive approach to the subject would require a 1000-page volume, and that may not be enough. Hence, we chose to select certain sectors that appear either to be moving quickly or that their further developments are likely to affect international affairs more than others; more specifically, we decided to focus on AI, robotics, space and satellites, computers, and networks. The latter in particular are cross-sectional, as without today's computing power, all technological research would still be years behind. The book is divided into three parts. 


\section{Part I: Technology and International Relations: Political, Economic and Ethical Aspects}

This first part of the book opens by setting some of the theoretical boundaries of the debate on technology and international power. In Chapter 1, 'Theorizing technology and international relations: prevailing perspectives and new horizons', Eriksson and Newlove-Eriksson provide an overview of the literature on technology and IR theory. First, the chapter considers how technology is treated in more general IR theory, including what role technology plays in the wider paradigmatic debates of IR. Second, the chapter scrutinizes attempts to develop specific theories on technology and international relations. Third, the chapter discusses the advantages and disadvantages of different approaches, including whether there are some areas that are amply theorized while others remain under-researched. In particular, the chapter addresses how and to what extent various approaches have been able to analyze the relationship between technological and societal change, both including the rapid development of new technologies (concerning, for example, cyber, nanotechnologies, space, robotics, and AI), and how technologies and critical infrastructures are becoming increasingly interconnected. Finally, the chapter suggests new horizons for empirically grounded theory on the relationship between technology and international society.

Chapter 2, 'Mapping technological innovation' by Moro and Valigi, focuses on how the global distribution of technological innovations changes, regardless of past investments and innovations influencing the ongoing trends in R\&D and patents. The attention devoted to patents and international standards-setting seems to increase as countries are securitizing their intellectual property - as shown by the case of China, whose patent applications have skyrocketed since 2000, overtaking the US in 2011. Regarding patents effectively granted by World Intellectual Property Organization (WIPO) offices, Asia is far ahead of other continents, and Africa and Latin America are at the lower margins. North America has grown irregularly, but doubled the number of granted patents since 1990, while the number for Europe considerably decreased, notwithstanding the vitality of some European firms. High-tech export in mature economies does not show significant differences among regions. On the contrary, looking at $\mathrm{R} \& \mathrm{D}$, remarkable differences among countries and regions exist. Japan and the US maintain the leading positions, China is quickly closing the gap, and the EU countries follow. Moving from these preliminary observations, the chapter then provides a map of technological innovation, also giving a clear representation of regional trends and their peculiarities by sectors.

Amoroso and Tamburrini follow with Chapter 3, 'Autonomy in weapons systems and its meaningful human control: a differentiated and prudential 
approach'. In the 2017 report by the Group of Governmental Experts on Lethal Autonomous Weapons Systems (LAWS), which met in Geneva under the auspices of the Convention on Certain Conventional Weapons, the need to further consider '[t]he human element in the use of lethal force' was emphasized. This need was already advocated - in far stronger terms - by the non-governmental organization (NGO) Article 36, which has long been making the case that meaningful human control (MHC) should be ensured over any weapons systems (including, but not limited to, lethal ones). However, while the notion of $\mathrm{MHC}$ is commonly viewed as a viable starting point for an international legal regulation on autonomous weapons, its precise content is still shrouded in controversy, giving rise to many conflicting interpretations as to what a veritable 'meaningful' human control should amount to.

Amoroso and Tamburrini provide a tentative answer or, at least, point a way forward to solving this challenging problem. Their working hypothesis is that the problem of establishing MHC does not lend itself to a one-size-fits-all solution achievable by endorsing one and only one of the various definitions propounded by states, NGOs, and scholars. Accordingly, they contend that, in the quest for 'meaningfulness' of human control over weapons systems, the international community should adopt a differentiated approach, grounded on ethical and legal principles: to be 'meaningful', in particular, human control over weapons systems should ensure compliance with the international rules regulating the use of lethal or sub-lethal force in armed conflicts and peacetime, and should avoid responsibility gaps in the case of harmful events affecting civilians or other protected persons. Such a principled approach leads to the identification of relevant properties (including timeframe of weapons system action, operational goals and context, human veto powers, human cognitive limitations and the increasing pace of war), and a suitable range of values for those properties in terms of which to assess the presence or else the lack of MHC on weapons systems. This methodology is applied to examine exemplary cases of weapons systems - including fire-and-forget munitions and swarming unmanned aerial vehicles (UAVs) - to evaluate whether each satisfies the MHC requirement.

\section{Part II: Robotics and Artificial Intelligence: Frontiers and Challenges}

The second part of the book begins with Chapter 4, 'Context matters: the transformative nature of drones on the battlefield' by Kreps and Maxey. Since drones are prevalent on contemporary battlefields, the authors ask to what extent and under what conditions such technology can be transformative. They tackle the question by evaluating two competing perspectives - one considers drones as transformative and destabilizing, the other views drones as just another platform. They also present an alternative, third way to evaluate 
drone proliferation that shows that the transformative nature of drones for the near future depends on the battlefield context. Drones for counterterrorism and non-state actors are likely to be more influential than in an interstate or intrastate conflict context. Drones for humanitarian intervention and peacekeeping purposes have untapped transformative potential. Ultimately, future generation drones that improve on stealth, speed, size, or ability to swarm are likely to have wider-ranging impacts across battlefield contexts.

Chapter 5 is, 'Artificial intelligence (AI): a paradigm shift in international law and politics? Autonomous weapon systems (AWS) as a case-study' by Martino and Merenda. The authors start by noting that, particularly in recent decades, AI has been revolutionizing modern societies in a wide range of different fields: AI devices are currently employed to assist judges, physicians, and soldiers with complex intellectual tasks. As technology further advances, not only the assistance of, but also the substitution of human beings with AI systems is being considered. Here, Martino and Merenda investigate the issue by considering a specific case study that is particularly relevant from an IR perspective: autonomous weapon systems (AWS) - namely, AI military robots that, allegedly, would not require human intervention in order to perform a military action. After an overall examination of the scholarly debate on AWS and a brief insight into the main technological questions involved, the authors consider the practice of AWS development and possible deployment by states and current international negotiations that consider their regulation or even outright prohibition.

\section{Part III: Space and Cyberspace: Intersection of Two Security Domains}

The book closes with four more contributions. The first is Chapter 6, 'The use of space: problems and challenges' by Anselmo, who reflects that international relations and technological change have been an integral part of the development of space activities for more than 60 years now. In fact, space is international, because any activity carried out in orbit around the Earth has implications for many, if not all, countries. Moreover, space has been the stage for fierce technological competition, with military, civilian, and commercial fallout. A growing number of important applications and critical functions depend on more than 1000 spacecraft, and this number might increase by one order of magnitude in the coming decade, with many public and private players, mostly newcomers. The challenges of the past could therefore pale compared with the new problems to be faced to guarantee a safe and responsible use of a resource and the emergence of new players in space, first and foremost China.

Colajanni and Marchetti are the authors of Chapter 7, 'Cyber attacks and defences: current capabilities and future trends'. Their contribution analyses 
the main capabilities and actors involved in the cyber landscape that represents a unique scenario for politics, military, intelligence, and companies. All of them are forced to play an asymmetric game where all the cards disadvantage the defenders. Anonymity, physical distance from targets, almost impossible attribution, known software vulnerabilities, inexpensive weapons based on human competences, and often free tools, are some of the features that attackers can leverage. On the other hand, the defense needs expensive frameworks and large numbers of competent and always active people who must guard increasing attacks. Therefore, there is a clear trend in investing in aggressive tools and in people more than in defensive technologies; moreover, it may not be the major Western countries that represent harmful adversaries, as several recent cases demonstrate. Colajanni and Marchetti conclude their work with a look at two emerging risk factors: the automation of cyber attacks on a large scale and the massive advent of the Internet of Things (IoT) and cyber-physical systems, representing a new battleground where people's safety will be the primary concern of cyber security. As the defenders are continuing to lose their battles and cyber threats involve the whole of society, it is time for a disruptive change to cyber security, requiring multicultural holistic approaches, positive application of well-known practices, and strong commitment of political and industrial management even when remedial actions may not be popular.

In Chapter 8, Locatelli considers the issue of 'critical infrastructure protection' (CIP) in his chapter of the same name. He begins by noting that, while it is widely accepted that cyber threats qualify as one of the major contemporary security issues, their real scope has been appreciated only recently. In particular, as seen most vividly with the 2017 spread of WannaCry ransomware, cyber offenders pose a serious societal threat. For this reason, CIP is increasingly being mentioned in national security documents all over the world. In this chapter, he presents a broad overview of the current literature on the topic. He thus begins with a concise description of the infrastructures that are currently deemed critical, with a view to showing the complexities of CIP; he then reviews the main policies devised in the US and the European Union (EU) to secure critical infrastructures (CIs). Finally, in the concluding section, he draws conclusions and discusses future avenues of research.

The last contribution, Chapter 9, 'A perfect storm: privatization, publicprivate partnership and the security of critical infrastructure' by Giacomello, is an exploratory examination of three 'historical' events that, in conjuncture but unintentionally, have increased the potential weaknesses of critical information infrastructures (CIIs) - those computer-managed assets like financial services, energy, telecommunications, transportation, and more, on which modern societies depend. The first event was the 'business Internetization' of data gathering and remote management of industrial control systems, which allowed businesses worldwide to reduce personnel costs and time manage- 
ment. The second was the 'privatization wave' of the 1980s, when utilities were privatized in the United States, Europe and elsewhere, under the conviction that the private sector could be more efficient in delivering the same services. Finally, the emergence of transnational public-private partnerships (PPPs) in the ownership and governance of utilities further aggravated the inherent CII vulnerabilities brought about by the 'privatization wave'. The chapter is thus an investigation of how such historical events can contribute to explain the origins of today's CII vulnerability.

\section{ACKNOWLEDGMENTS}

The book is the offspring of a workshop held at the Fondazione Bruno Kessler (Trento) in December 2016 and organized under the auspices of the NATO Allied Command Transformation (NATO ACT) and Alma Mater Studiorum - University of Bologna. Some of the key concepts related to technological change, military transformation, and adaptation of complex social organizations to innovation became the backbone of this book. For this reason, we would like the thank the Director of the Research Center on International Politics and Conflict Resolution (CeRPIC) of the Fondazione Bruno Kessler, Professor Filippo Andreatta, the scholars that contributed to the debate, and Professor Sonia Lucarelli, who coordinates scientific and dissemination activities between the University of Bologna and NATO ACT.

\section{REFERENCES}

Brooks, Stephen G. (2007), Producing Security: Multinational Corporations, Globalization, and the Changing Calculus of Conflict, Princeton, NJ: Princeton University Press.

Brosnan, Mark J. (2002), Technophobia: The Psychological Impact of Information Technology, Abingdon: Routledge.

Dinello, Daniel (2005), Technophobia! Science Fiction Visions of Posthuman Technology, Austin, TX: University of Texas Press.

Fearon, James D. (1994), 'Domestic political audiences and the escalation of international disputes', American Political Science Review, 88(3), 577-92.

Fritsch, Stefan (2011), 'Technology and global affairs', International Studies Perspectives, 12(1), 27-45.

Hanson, Elizabeth (2008), The Information Revolution and World Politics, Lanham, MD: Rowman \& Littlefield.

Herrera, Geoffrey L. (2006), Technology and International Transformation: The Railroad, the Atom Bomb, and the Politics of Technological Change, Albany, NY: State University of New York Press.

Horowitz, Michael C. (2010), The Diffusion of Military Power: Causes and Consequences for International Politics, Princeton, NJ: Princeton University Press. 
Kissinger, Henry (2018), 'How the enlightenment ends', The Atlantic, June, accessed 25 January 2020 at https://www.theatlantic.com/magazine/archive/2018/06/henry -kissinger-ai-could-mean-the-end-of-human-history/559124/.

Krepinevich, Andrew F. (1994), 'Cavalry to computer: the pattern of military revolutions', The National Interest, 1 September, accessed 25 January 2020 at https:// nationalinterest.org/article/cavalry-to-computer-the-pattern-of-military-revolutions -848 .

McNeill, William H. (1982), The Pursuit of Power: Technology, Armed Force, and Society since A.D. 1000, Chicago, IL: University of Chicago Press.

Ogburn, William F. (ed.) (1949), Technology and International Relations, Chicago, IL: University of Chicago Press.

Powell, Robert (1999), In the Shadow of Power: States and Strategies in International Politics, Princeton, NJ: Princeton University Press.

Sanders, Ralph (1983), International Dynamics of Technology, Westport, CT: Greenwood Press.

Singer, Peter W. (2009), Wired for War: The Robotics Revolution and Conflict in the 21st Century, New York: Penguin Books.

Sismondo, Sergio (2004), An Introduction to Science and Technology Studies, Malden, MA and Oxford: Blackwell Publishing.

Skolinkoff, Eugene B. (1993), The Elusive Transformation: Science, Technology, and the Evolution of International Politics, Princeton, NJ: Princeton University Press.

Smith, Alastair and Allan C. Stam (2004), 'Bargaining and the nature of war', Journal of Conflict Resolution, 48(6), 783-813.

Smith, Merritt R. and Leo Marx (eds) (1994), Does Technology Drive History? The Dilemma of Technological Determinism, Cambridge, MA: MIT Press.

van Creveld, Martin (1989), Technology and War: From 2000 B.C. to the Present, Newark, NJ: Free Press.

Vig, Norman J. (1988), 'Technology, philosophy, and the state: an overview', in Michael E. Kraft and Norman J. Vig (eds), Technology and Politics, Durham, NC: Duke University Press.

Winner, Langdon (1977), Autonomous Technology: Technics-out-of-Control as a Theme in Political Thought, Cambridge, MA: MIT Press.

Winner, Langdon (1986), The Whale and the Reactor: A Search for Limits in an Age of High Technology, Chicago, IL: Chicago University Press. 
Giampiero Giacomello, Francesco Niccolò Moro, and Marco Valigi - 9781788976077 Downloaded from PubFactory at 04/26/2023 12:20:22PM 